\title{
Iranian EFL Learner's Communication Strategies: Emails to Instructors
}

\author{
Atefe Sobhani (Corresponding author) \\ English Department, Islamic Azad University, Torbat-e-Heidarieh Branch, Iran \\ Email: atefe.sobhani@gmail.com \\ Khalil Motallebzadeh \\ English Department, Islamic Azad University, Torbat-e-Heidarieh Branch, Iran \\ Email: k.motalleb@iautorbat.ac.ir \\ Hamid Ashraf \\ English Department, Islamic Azad University, Torbat-e-Heidarieh Branch, Iran \\ Email: h.ashraf@iautorbat.ac.ir
}

Received: 25-10-2013

Accepted: 05-12-2013

Published: 01-03-2014

doi:10.7575/aiac.ijalel.v.3n.2p.64

URL: http://dx.doi.org/10.7575/aiac.ijalel.v.3n.2p.64

\begin{abstract}
Email has become a widespread medium of communication between students and their instructors, however; there is a limited amount of research on instructional role and uses of email in academic context. The present study investigated the communication strategies in email messages sent by Iranian EFL students to their male instructors in relation to their socioeconomic status (such as family income and education level). Moreover, the relationships between communication strategies and gender were examined. Email message sent by male and female students to their male instructors during the academic year 2012-2013 were analyzed for communication strategies (requesting, negotiating, reporting, social). The results of quantitative and qualitative statistics revealed that there were significant relationships between communication strategies and participants' socioeconomic status. In addition, there were significant relationships between communication strategies and gender.
\end{abstract}

Keywords: Email communication, Communication strategies, socioeconomic status, gender

\section{Introduction}

Technology has brought a paradigm shift in social life and communication. Computer-mediated communication (CMC) has impacted the daily life of people and their interactions. With the advent of information communication technology (ICT) and Internet, people have had the opportunities to use services such as electronic mail or instant messaging, the means by which they obtain and maintain social communications (Rice, Shepherd, Dutton \& Katz, 2007). It is noteworthy that internet has become daily communication habits for college students who are wide users of internet (Jones, 2002). Communicative competence could be used in two modes of synchronous and asynchronous. In educational contexts, asynchronous mediums such as email and discussion groups were preferred to synchronous tools (Hsu, Wang, \& Comac, 2008; Hurd \& Murphy, 2005). Research on CMC and email as an asynchronous form of CMC has started to develop. What has made the CMC research area difficult is the fact that researchers have investigated it from different perspectives (Recchiuti, 2003). Regarding internet use, "there is cause for concern with regard to some of the more vulnerable groups (families with young children, the unemployed, the physically and socially isolated, the elderly, disabled people and those living in rural and remote areas) where a complex set of factors can restrict internet access and use" (Jones, 2010, p. 3).

While all around the world variety of studies have been conducted on topics, purposes and communicative strategies employed by university students in email interactions, a limited number of researches have been investigated in Iran (Chalak, Eslami \& Eslami, 2010; Samar, Navidian \& Mehrani, 2010; Izadi \& Zilaie, 2012). Furthermore, the studies which examine the effects of factors as socioeconomic status and gender in using internet and email are in the earliest stages. It seems that Iranian students have insufficient competency to employ appropriate strategies (Samar, Navidian \& Mehrani, 2010). Since electronic mail is a convenient tool to communicate at anytime and anywhere, Iranian teachers and syllabus designers should consider students' academic needs and provide courses to teach them how to use email appropriately for exchanging knowledge, negotiating meaning, establishing and maintaining social relationships in educational context. 


\subsection{Review of Literature}

\subsubsection{Email Communication in Academic Context}

Email contains both spoken and written features of discourse (Uhlirova, 1994). Comparing printed text as a traditional mode of communication with email revealed that email was as persuasive as printed text (Hill and Monk, 2000). Some researchers believe that email is a channel between instructors and students which is used to transmit knowledge. As email is a supplementary tool in teaching and improving students' performances, both students and instructors benefit email communication in educational context (Smith, Whiteley \& Smith, 1999; Boles, 1999). Email has been applied for many purposes such as, making excuse, establishing relationships with teachers, negotiating meaning and giving or receiving input/feedback (Biesenbach-Lucas, 2005; Gee, 2002; Bloch, 2002; Payne, 1997; Poling 1994; Martin, Myers \& Mottete, 1999). Furthermore, Duran, Kelly \& Keaten, (2005) found that the most frequent motives was excusing applied by students. Faculty received more emails than they initiated and faculty members considered email as a tool of communication which was beneficial in academic context. Likewise, Martin, Mottetand, Myers (2000) investigated the reasons and communication motives for which students communicated with their instructors via email. In a factor analysis, it was revealed that students sent email for five reasons such as relational and excuses. Moreover, canonical correlation proved that there was a relationship between students' trait interpersonal communication motives and the five reasons.

In a study conducted by Biesenbach-Lucas (2005), three communication strategies and topics of email messages were analyzed. The subjects were American and international students who sent email messages to their professors. It was indicated that facilitative topic is the most frequent communication topics; however, American used facilitative topics more than international students. American students were more competent in employing communication strategies (such as negotiating project topics) both quantitatively and qualitatively than international students. Two years later, Biesenbach-Lucas (2007) examined the email requests among native and non-native students. It was found that both groups used the same general strategies but they understand them differently. As situational factors influence requests, these email requests of faculty were not considered equal by NSs and NNSs. Similarly, Samar, Navidinia \& Mehrani (2010) examined the communication purposes and strategies used by Iranian and American TEFL students in their email interactions with their instructors. The findings showed American students applied more communication strategies along with personal and social purposes. Chalak, Eslami-Rasekh \& Eslami-Rasekh (2010) investigated communicative strategies and topics applied by Iranian EFL students. The participants of the research were at undergraduate and graduate levels. The results demonstrated that students at two levels used requesting more than other strategies and students at different groups employed different topics for communications.

Moreover, Motallebzadeh (2011) examined the effect of emailing tasks on the reading comprehension ability of Iranian EFL learners. The findings illustrated that emailing tasks had a significant effect on Iranian EFL learners' comprehension ability. While, there was a significant difference between the students' performances on seen passage sections in the experimental and control groups, there was no significant effect between the students' performances on unseen passages sections. Additionally, Fahim, Motallebzadeh and Sazegar (2011) explored the effect of emailing on vocabulary retention of Iranian EFL learners. The results revealed that email has a positive effect on vocabulary retention and can be employed as an effective tool in learning vocabularies.

\subsubsection{Socioeconomic Status and Gender}

The effect of socioeconomic status in students' achievements and their level of proficiency is observable (Datcher as cited in Papanis, Giavrinis \& Papani, 2010). Jackon, Samona and Moomaw (2007) claimed that there was a relationship between socioeconomic status and Internet use. Lower socioeconomic status decreased the use of Internet, whereas higher level of socioeconomic status increased the use of Internet. It was argued that there was a relationship between SES and online abilities, searching web and spending time online (Gui \& Argentin, 2011). Herring (1994) expressed that the presence of a power in teacher-student relationships in educational setting make the interaction different from that with friends or classmates. Relationship distance and the degree of power influence email communication. Similarly, Janghorban \& Ketabi (2011) found a significant difference between the emails sent to teachers and friends with regard to formality level and discourse features. It was proved that social distance has an important role for Iranian students in their email communication.

"Gender is the difference between woman and men resulted from cultural and social expectation. Gender roles vary widely within the same culture and they also differ from each other among cultures" (Ning, Dai and Zhang, 2010, p. 127). Tannen (1990) illustrated the differences between males and females in applying conversational strategies. Herring (1994) claimed men and women don't use same communicative styles in working online and posting to the internet. While, females try to support, apologize, express appreciation, doubt in online communication, males reveal their own perspective, criticize others by using an adversarial style in their frequent and lengthy posts. Ning, Dai and Zhang (2012) believed that females express their request indirectly, but males express their request or order in a direct way with few words. Vernacular words are used by men more than women. Moreover, Herring (1993) explained that email messages written by male and female individuals could be identified from linguistic and rhetorical strategies. Maybe men's language included strong, authoritative and humorous statements with rhetorical questions, on the contrary; women's language probably included weak, supportive and personal statements with questions and apologies. In addition, Weiser (2000) presented that younger people and females preferred to interact via email more than others. In the same way, Rossetti (2000) observed that there were significant gender differences in email communication. He analyzed email messages in electronic discussion groups. There was language style dichotomy both in real 
communication and in email interaction. Males tried to enhance their authority and respect while females had supportive role and improved their relationships with others. Duran, Kelly \& Keaten, (2005) investigated that female instructors reported that they received more email from students than male instructors. In a research which was carried out to discover differences in communication topics, communication strategies and address terms of email messages sent by Saudi Female students to their male professors. Communication topics as facilitative, substantive, relational and communication strategies as requesting, negotiating, reporting were analyzed. There was no significant difference in frequency of communication topics; however, it was demonstrated that requesting had the highest frequency in communication strategies (Bulut \& Rabab'ah, 2007). No study has explored the probable relationship between socioeconomic status, gender and communication strategies in email communication between Iranian EFL learners and their instructors. To determine probable relationships, the researchers focused on the studies related to the mentioned variables.

\subsubsection{Purpose of the Study}

In this study, the researcher is interested in finding how Iranian EFL students use communication strategies with regard to socioeconomic status in email communications with their male instructors. Moreover, the study aims to examine gender differences in email interactions between university students and their male instructors. To achieve the abovementioned purposes, the researchers proposed the following questions:

Q1. Are there any significant differences between communication strategies employed by Iranian EFL students and their socioeconomic status in email communications with male university instructors?

Q2. Are there any significant relationships between gender differences and communication strategies employed by Iranian EFL students in email communications with their male university instructors?

\section{Method}

\subsection{Data, Participants, and Variables}

The data for this study represents a subset of a large corpus comprising of 450 e-mail messages. To avoid any probable effects, it was decided to work on student-initiated rather than teacher-initiated emails. Emails were authentic data that represented the actual communication strategies that male/female students applied in their e-mail messages to their male instructors. Students were all familiar with sending and receiving e-mails. Email messages were sent by 86 Iranian MA students majoring in Teaching English as a Foreign Language (TEFL), English Translation, and English Language Literature during two semesters to their male professors. Participants were studying at different universities in different provinces of Iran such as Khorasan Razavi, Tehran and Semnan. They were both male and female native speakers of Farsi, and their age ranged between 23 and 43. The instructors to whom emails were sent were Iranian non-native speakers of English, middle aged male instructors with teaching experience at university level. E-mail messages sent to female instructors were not included. Variables of the present study are communication strategies, socioeconomic status and gender. The frequencies and percentages for each group such as age, gender and field of study were computed in the following table:

Table 1. Demographic Analysis

\begin{tabular}{|c|c|c|c|c|c|}
\hline & & Frequency & Percent & Valid Percent & Culmulative Percent \\
\hline \multirow[t]{4}{*}{ Age } & $23-29$ & 72 & 83.7 & 83.7 & 83.7 \\
\hline & $30-36$ & 10 & 11.6 & 11.6 & 95.3 \\
\hline & $37-43$ & 4 & 4.7 & 4.7 & 100.0 \\
\hline & Total & 86 & 100.0 & 100.0 & \\
\hline \multirow[t]{3}{*}{ Gender } & Female & 66 & 76.7 & 76.7 & 76.7 \\
\hline & Male & 20 & 23.3 & 23.3 & 100.0 \\
\hline & Total & 86 & 100.0 & 100.0 & \\
\hline \multirow{5}{*}{$\begin{array}{l}\text { Nnumber of people } \\
\text { in family }\end{array}$} & 1 & 2 & 2.3 & 2.3 & 2.3 \\
\hline & 2 & 8 & 9.3 & 9.3 & 11.6 \\
\hline & 3 & 19 & 22.1 & 22.1 & 33.7 \\
\hline & 4 /more than 4 & 57 & 66.3 & 66.3 & 100.0 \\
\hline & Total & 86 & 100.0 & 100.0 & \\
\hline \multirow[t]{4}{*}{ Province } & Tehran & 15 & 17.4 & 17.4 & 17.4 \\
\hline & Khorasan Razavi & 47 & 54.7 & 54.7 & 72.1 \\
\hline & Others & 24 & 27.9 & 27.9 & 100.0 \\
\hline & Total & 86 & 100.0 & 100.0 & \\
\hline \multirow[t]{3}{*}{ Marital status } & Single & 58 & 67.4 & 67.4 & 67.4 \\
\hline & Married & 28 & 32.6 & 32.6 & 100.0 \\
\hline & Total & 86 & 100.0 & 100.0 & \\
\hline \multirow[t]{3}{*}{ Field of study } & EFL & 37 & 43.0 & 43.0 & 43.0 \\
\hline & English Translation & 49 & 57.0 & 57.0 & 100.0 \\
\hline & Total & 86 & 100.0 & 100.0 & \\
\hline
\end{tabular}




\subsection{Analytical Framework}

The analytical framework chosen for this study was that of Chalak et al. (2010) who had followed Biesenbach-Lucas (2005). Chalak et al. (2010) defined and subdivided each of the communication strategies (requesting, reporting and negotiating) as indicated in Table 2. The adopted scheme used to categorize the contents of the emails for communication strategies. Furthermore, social strategy was added by the researchers to cover emails which contained social strategy for interacting with male instructors.

Table 2. Communication Strategies

\begin{tabular}{cll}
\hline Communicative Strategies & \multicolumn{1}{c}{ Subdivisions } \\
\hline & 1. & Request for appointment \\
& 2. & Request for explanation \\
& 3. & Request for extension of due date \\
& 4. & Request for feedback \\
Requesting & 5. & Request for grade \\
& $6 . \quad$ Request for help \\
& $7 . \quad$ Request for information \\
& $8 . \quad$ Request for translation \\
& $9 . \quad$ Request for s.th \\
\hline Reporting & Mainly declarative statements \\
\hline Negotiating & Request of approval/ Permission to continue a \\
& project, research, or plan \\
\hline Social & Mainly declarative statements \\
\hline (a researcher-added strategy) & \\
\hline
\end{tabular}

Drawing on pragmatic analysis approaches in relation to sociolinguistic perspective, the present study aimed at proving insights into content-specific pragmatic within the student- teacher email interaction for communication strategies and adapted a qualitative and quantitative method for analyzing and describing the relationship between communication strategies, socioeconomic status, gender in e-mail messages written in English by Iranian male and female students as non-native English speakers to their male instructors.

\subsection{Instrument and Data Analysis Procedure}

Four hundred fifty email messages, which were sent by Iranian MA students to their male professor, were collected during 2012-2013 over two semesters to examine communication strategies in email interactions.

The emails in Persian or with English script in Persian, and emails without text were excluded from the data. Moreover, messages with sensitive or confidential information were not used in data analysis. With regard to ethical issues, participants were informed that their email messages were stored to be used in the research and their personal information were kept confidential. The researchers then analyzed each corpus separately identifying communication strategies based on the model given by Chalack et al. (2010). With regard to the fact that each email might have included more than one communication strategy, the sentence was considered as the unit of analysis rather than the whole email itself. Therefore, an email could include more than one strategy.

The researchers used a questionnaire, which included 17 questions to gather information about participant socioeconomic status, years of experience using email, and amount of weekly email use in addition to some questions regarding age, sex, and province. The questionnaire was designed and then validated by two experts in the area of ELT, and the reliability was calculated in a pilot study including 20 students from similar population using Cronbach's Alpha $(\mathrm{r}=0.7)$. Students spent 10 minutes to complete this questionnaire. The information from questionnaire were applied to examine the probable relationships between socioeconomic status, age, gender and the percentage of communication strategies. The data were analyzed using SPSS software16.0 (2007). Then they were calculated and interpreted in terms of descriptive statistics, frequencies/percentages, and correlation. Pearson correlation coefficient and Mann-Whitney Test were employed to reveal the probable relationships between communication strategies, socioeconomic status, and gender.

\section{Results and Discussion}

\subsection{Descriptive Analysis}

\subsubsection{Email analysis}

Each email might have included more than one communication strategy, since the sentence was considered as the unit of analysis rather than the whole email itself. The following are examples of the communication strategies from the data:

\section{Requesting:}

-I need a recommendation letter for the interview. I wonder if it is possible for you to kindly write me the letter.

-Please check the suggested activities below and let us know your opinion. 
Reporting:

-I modified the power point file as you said; I added two other tables, and the slides appear just by one click.

-Up to now, I have managed to collect three journals for each discipline and to select 10 articles from each journal.

Negotiating:

-Would you please see the items and let me know what other changes you think are still needed?

-I need your confirmation before I begin the study.

Social:

-How are you? Hope to be great!

I'm a little concerned about you since I have not had any mail from you for at least 2 weeks!!! Are you OK and Healthy?? I hope so.

-Happy Happy New Year!I Wish U All The Best!

The analysis of email messages sent by Iranian MA students revealed that the participants used all the communication strategies.

\subsection{Statistical Analysis}

\subsubsection{Socioeconomic status and communication strategies}

Pearson correlation coefficient was computed to answer first research question.

Q1. Are there any significant relationships between communication strategies employed by Iranian EFL students and their socioeconomic status in email communications with male university instructors?

Table 3. The Results of Correlation between Social Status and Communication Strategies

\begin{tabular}{lcc}
\hline \multicolumn{1}{c}{ Social status } & P-Value & Pearson correlation coefficient \\
\hline 1. Requesting strategy (Strategy1-9) & $0 / 083$ & $0-/ 188$ \\
1.1 Request for appointment & $0 / 437$ & $0-/ 085$ \\
1.2 Request for explanation & $0 / 522$ & $0 / 070$ \\
1.3 Request for extension of due date & $0 / 29$ & $0-/ 115$ \\
1.4 Request for feedback & $0 / 205$ & $0-/ 138$ \\
1.5 Request for grade & $0 / 148$ & $0-/ 157$ \\
1.6 Request for help & $0 / 396$ & $0 / 093$ \\
1.7 Request for information & $0 / 122$ & $0-/ 168$ \\
1.8 Request for translation & $0 / 122$ & $0 / 061$ \\
1.9 Request for something & $0 / 168$ & $0-/ 150$ \\
2. Reporting strategy & $0 / 016$ & $0-/ 258$ \\
3. Negotiating strategy & $0 / 007$ & $0-/ 289$ \\
4. Social strategy & $0 / 536$ & $0-/ 069$ \\
\hline
\end{tabular}

As shown in Table 3, reporting strategy $(r=-0.258, \mathrm{p}<0.016)$ and negotiating strategy $(\mathrm{r}=-0.289, \mathrm{p}<0.007)$ suggest that a participant's social status relates to his or her use of these strategies in email messages.

Table 4. The Results of Correlation between Economic Status and Communication Strategies

\begin{tabular}{lcc}
\hline \multicolumn{1}{c}{ Economic status } & P-Value & Pearson correlation coefficient \\
\hline 1. Requesting strategy (Strategy 1-9) & $0 / 138$ & $-0 / 161$ \\
1.1 Request for appointment & $0 / 911$ & $-0 / 012$ \\
1.2 Request for explanation & $0 / 426$ & $-0 / 087$ \\
1.3 Request for extension of due date & $0 / 308$ & $-0 / 111$ \\
1.4 Request for feedback & $0 / 257$ & $-0 / 124$ \\
1.5 Request for grade & $0 / 493$ & $-0 / 075$ \\
1.6 Request for help & $0 / 147$ & $-0 / 158$ \\
1.7 Request for information & $0 / 216$ & $-0 / 135$ \\
1.8 Request for translation & $0 / 973$ & $-0 / 004$ \\
1.9 Request for something & $0 / 310$ & $-0 / 111$ \\
2. Reporting strategy & $0 / 051$ & $-0 / 211$ \\
3. Negotiating strategy & $0 / 297$ & $-0 / 114$ \\
4. Social strategy & $0 / 016$ & $-0 / 264$ \\
\hline
\end{tabular}

The correlation coefficients presented in Table 4 depicts that participants' economic status has an impact on social strategy $(r=-0.264, p<0.016)$ used in their email messages. 
Table 5 displays the results of correlation for the relationship between communication strategies and students' socioeconomic status.

Table 5. The Results of Correlation between Socioeconomic Status and Communication Strategies

\begin{tabular}{lcc}
\hline \multicolumn{1}{c}{ Socioeconomic status } & P-Value & Pearson correlation coefficient \\
\hline 1. Requesting strategy (Strategy 1-9) & $0 / 779$ & $-0 / 031$ \\
1.1 Request for appointment & $0 / 623$ & $-0 / 054$ \\
1.2 Request for explanation & $0 / 764$ & $-0 / 033$ \\
1.3 Request for extension of due date & $0 / 174$ & $-0 / 148$ \\
1.4 Request for feedback & $0 / 807$ & $-0 / 027$ \\
1.5 Request for grade & $0 / 195$ & $-0 / 141$ \\
1.6 Request for help & $0 / 110$ & $-0 / 173$ \\
1.7 Request for information & $0 / 855$ & $-0 / 020$ \\
1.8 Request for translation & $0 / 752$ & $-0 / 035$ \\
1.9 Request for something & $0 / 924$ & $-0 / 010$ \\
2. Reporting strategy & $0 / 756$ & $-0 / 034$ \\
3. Negotiating strategy & $0 / 587$ & $-0 / 059$ \\
4. Social strategy & $0 / 119$ & $-0 / 172$ \\
\hline
\end{tabular}

Table 5 lists the correlation coefficients with effect sizes for each communication strategies. In terms of socioeconomic status, negative relationships were detected (Table 5) suggesting socioeconomic status didn't correlate to communication strategies.

Jackson, Samona and Moomaw (2007) believed that higher level of socioeconomic status increase the use of internet. It is assumed that people from university population and from greater income or wealth apply internet more than others (Schell, 2007). In other words, there is a relationship between ESE and online abilities and activities (Gui \& Argentin, 2011). Nasah, et al. (2010) argued that students with high family annual income access to information via ICT more than students with low family annual income. However, it doesn't a determining factor in using different forms of ICT. Previous researches support the results of current study.

It is clear that although socioeconomic status didn't impact the use of communication strategies (Table 5). It appeared that social and economic status in separate can be influential factors in using above mentioned strategies in email messages. It means that there was a significant relationship between students' educational level, reporting strategy and negotiating strategy (Table 3). Moreover, it was proved that there was a significant relationship between social strategy and participants' economic status (Table 4). Thus, the first null hypothesis that claimed there is no significant relationship between communication strategies and socioeconomic status in email communication is rejected.

\subsubsection{Gender and communication strategies}

The second interest of this study was to determine if there were any relationships between gender and communication strategies in email communications. Mann-Whitney Test was used to examine the second null research hypothesis and the results are indicated in the following tables (Table 6).

Table 6. Gender and Requesting Strategy (strategy 1-9)

\begin{tabular}{|c|c|c|c|}
\hline & Gender & $\mathrm{N}$ & Mean Rank \\
\hline \multirow[t]{9}{*}{ Strategy 1-9 } & Female & 66 & 38.01 \\
\hline & Male & 20 & 61.63 \\
\hline & Total & 86 & \\
\hline & \multicolumn{3}{|c|}{ Test Statistics $^{\mathrm{a}}$} \\
\hline & & & Strategy 1-9 \\
\hline & Mann-W & & 297.500 \\
\hline & Wilcoxo & & 2508.500 \\
\hline & $\mathrm{Z}$ & & -3.825 \\
\hline & Asymp. & led) & .000 \\
\hline
\end{tabular}

a. Grouping Variable: Gender

Table 6 highlights the results of Mann-Whitney $U$ Test that there is a significant relationship $(\mathrm{p}=0.000<0.05)$ between male $(M=59.53)$ and female groups $(M=38.64)$ in using requesting strategy. The following table indicates the findings of Mann-Whitney U Test for gender and subdivisions of requesting strategy. 
Table 7. Gender and Requesting Strategy (subdivisions)

\begin{tabular}{|c|c|c|c|c|c|c|c|c|}
\hline \multicolumn{2}{|l|}{ RequestGender } & $\mathrm{N}$ & $\begin{array}{l}\text { Mean } \\
\text { Rank }\end{array}$ & $\begin{array}{c}\text { Sum } \\
\text { of Ranks }\end{array}$ & $\begin{array}{c}\text { Mann- } \\
\text { Whitney U }\end{array}$ & Wilcoxon W & Z & $\begin{array}{l}\text { Asymp. Sig } \\
\text { (2-tailed) }\end{array}$ \\
\hline \multirow[t]{3}{*}{ Appointment } & Female & 66 & 43.47 & 2869.00 & 658.000 & 2869.000 & -.056 & .955 \\
\hline & Male & 20 & 43.60 & 872.00 & & & & \\
\hline & Total & 86 & & & & & & \\
\hline \multirow[t]{3}{*}{ Explanation } & Female & 66 & 43.15 & 2848.00 & 637.000 & 2848.000 & -.901 & .368 \\
\hline & Male & 20 & 44.65 & 893.00 & & & & \\
\hline & Total & 86 & & & & & & \\
\hline \multirow{3}{*}{$\begin{array}{l}\text { Extension } \\
\text { of due date }\end{array}$} & Female & 66 & 43.65 & 2881.00 & 650.000 & 860.000 & -.550 & .582 \\
\hline & Male & 20 & 43.00 & 860.00 & & & & \\
\hline & Total & 86 & & & & & & \\
\hline \multirow[t]{3}{*}{ Feedback } & Female & 66 & 39.48 & 2606.00 & 395.000 & 2606.000 & -.3 .106 & .002 \\
\hline & Male & 20 & 56.75 & 1135.00 & & & & \\
\hline & Total & 86 & & & & & & \\
\hline \multirow[t]{3}{*}{ Grade } & Female & 66 & 43.86 & 2895.00 & 636.000 & 846.000 & -.518 & .605 \\
\hline & Male & 20 & 42.30 & 846.00 & & & & \\
\hline & Total & 86 & & & & & & \\
\hline \multirow[t]{3}{*}{ Help } & Female & 66 & 42.38 & 2797.00 & 586.000 & 2797.000 & -1.027 & .304 \\
\hline & Male & 20 & 47.20 & 944.00 & & & & \\
\hline & Total & 86 & & & & & & \\
\hline \multirow[t]{3}{*}{ Information } & Female & 66 & 40.04 & 2642.50 & 431.500 & 2642.000 & -3.108 & .002 \\
\hline & Male & 20 & 54.93 & 1098.50 & & & & \\
\hline & Total & 86 & & & & & & \\
\hline \multirow[t]{3}{*}{ Translation } & Female & 66 & 43.00 & 2838.00 & 627.000 & 2838.000 & -1.817 & .069 \\
\hline & Male & 20 & 45.15 & 903.00 & & & & \\
\hline & Total & 86 & & & & & & \\
\hline \multirow[t]{3}{*}{ Something } & Female & 66 & 38.51 & 2541.50 & 330.500 & 2541.500 & -3.906 & .000 \\
\hline & Male & 20 & 59.98 & 1199.50 & & & & \\
\hline & Total & 86 & & & & & & \\
\hline
\end{tabular}

Grouping Variable: Gender

The above table (Table 7) shows the results of Mann-Whitney Test for the relationship between gender and subdivisions of requesting strategies. It was found that there was a significant relationship between gender and request for feedback $(\mathrm{p}=0.002<0.05)$. Moreover, a significant relationship was revealed between gender and request for something $(\mathrm{p}=$ $0.000<0.05)$. However, the differences between male and female students in using other strategies as request for appointment $(\mathrm{p}=0.955>0.05)$, explanation $(\mathrm{p}=0.368>0.05)$, extension of due date $(\mathrm{p}=0.582>0.05)$, grade $(\mathrm{p}=$ $0.605>0.05$, sig $=.605)$, help $(\mathrm{p}=0.304>0.05)$, information $(\mathrm{p}=0.955>0.05)$ and translation $(\mathrm{p}=0.069>0.05)$ suggested that there were no significant relationships between gender and mentioned strategies.

Table 8. Gender and Reporting Strategy

\begin{tabular}{lclcc}
\hline Gender & & N & Mean Rank & Sum of Ranks \\
\hline Reporting strategy & Female & 66 & 38.64 & 2550.50 \\
& Male & 20 & 59.53 & 1190.50 \\
& Total & 86 & & \\
\hline
\end{tabular}

\begin{tabular}{lc}
\multicolumn{2}{c}{ Test Statistics $^{\mathrm{a}}$} \\
\hline & Reporting strategy $^{2}$ \\
\hline Mann-Whitney U & 339.500 \\
Wilcoxon W & 2550.500 \\
Z & -3.369 \\
Asymp. Sig. (2-tailed) & .001 \\
\hline
\end{tabular}

a. Grouping Variable: Gender

According to results in Table 8, male participants $(\mathrm{M}=59.53)$ used reporting strategies more than female students $(\mathrm{M}=$ 38.64).The results proved the significant relationship between reporting strategy and gender $(p=0.001<0.05)$. 


\begin{tabular}{ccccc}
\multicolumn{5}{l}{ Table 9. Gender and Negotiating Strategy } \\
& Gender & $\mathrm{N}$ & Mean Rank & Sum of Ranks \\
\hline Negotiating strategy & Female & 66 & 41.10 & 2712.50 \\
& Male & 20 & 51.43 & 1028.50 \\
& Total & 86 & & \\
\hline
\end{tabular}

\begin{tabular}{lc}
\multicolumn{2}{c}{ Test Statistics $^{\mathrm{a}}$} \\
\hline \multicolumn{2}{c}{ Negotiating strategy $^{2}$} \\
\hline Mann-Whitney U & 501.500 \\
Wilcoxon W & 2712.500 \\
Z & -2.051 \\
Asymp. Sig. (2-tailed) & .040 \\
\hline
\end{tabular}

a. Grouping Variable: Gender

As Table 9 indicates, there is a significant relationship $(p=0.040<0.05)$ between females $(M=41.1)$ and males $(M=$ 51.43) in applying negotiating strategies. Table 10 displays the result of Mann-Whitney U Test for social strategy and gender.

Table 10. Gender and Social Strategy

\begin{tabular}{lllcc}
\hline & Gender & N & Mean Rank & Sum of Ranks \\
\hline Social strategy & Female & 63 & 37.52 & 2364.00 \\
& Male & 20 & 56.10 & 1122.00 \\
& Total & 83 & & \\
\hline
\end{tabular}

\begin{tabular}{lc}
\multicolumn{2}{c}{ Test Statistics $^{\mathrm{a}}$} \\
\hline \multicolumn{2}{c}{ Social strategy $^{2}$} \\
\hline Mann-Whitney U & 348.000 \\
Wilcoxon W & 2364.000 \\
Z & -3.265 \\
Asymp. Sig. (2-tailed) & .001 \\
\hline
\end{tabular}

a. Grouping Variable: Gender

As can be seen in Table 10, the result illustrates a significant relationship between gender and social strategies $(\mathrm{p}=$ $0.001<0.05)$. It means that female students $(\mathrm{M}=37.52)$ used social strategy less than male students $(\mathrm{M}=56.10)$.

It was suggested that men and women don't have the same tendencies to email communication (Zack, 1993). Zare (as cited in Abbasian, Khajavi \& Mardani, 2012) found that gender differences are significant in language learning strategies applied by Iranian EFL learners. Furthermore, Tannen (as cited in Salmani-Nodoushan, 2007) illustrated the differences between males and females in applying conversational strategies. Similarly, Salmani-Nodoushan (2007) found that men and women applied two conversational strategies differently. In other words, they used expressing emotions and providing rhetoric differently. The evidences support gender differences for applying communication strategies in this study. Since, men try to use language as a tool to achieve their goals (Savicki, Foster \& Kelley, 2006) and focus on content in their email communications, it seems that they try to apply communication strategies more than females to communicate via email. Moreover, there are differences between male and female students in using communication strategies in their email communications.

\section{Conclusion and Pedagogical Implications}

Several studies have focused on issues of socioeconomic (Gui \& Argentin, 2011; Jackson, Samona \& Moomaw, 2007) and gender (Brosnan, 2006; Sheehan, 1999;) in applying internet and online communication, especially gender differences in email communications (Duran, Kelly \& Keaten, 2005; Mulac, Seibold, \& Farris, 2000). This study continued this line of research by examining communication strategies in email messages written by MA students in relation to their socioeconomic status and gender.

Despite the research limitations, such as a limited amount of research concerning the use of e-mail in the educational context and the number of participants, this study provides a wealth of information about communication strategies used by university students in email communications.

Two fundamental questions and null hypotheses were proposed. First hypothesis which claimed that there aren't any significant relationships between communication strategies employed by Iranian EFL students and their socioeconomic status in email communications was rejected. The results found that there are significant differences in applying communication strategies with regard to participants' social and economic status such as education level and family income. Taken together, these findings mirror those in Samona and Moomaw (2007), Schell (2007), Gui and Argentin (2011) studies which revealed the relationships between socioeconomic status and internet use/online activities. 
Another hypothesis was that there aren't any significant differences between communication strategies used by Iranian EFL students and gender differences. The current study proved that there is a significant relationship between gender and communication strategies applied by students in email communication with their male instructors. Thus, the second null hypothesis was rejected. The findings indicated that male students employed communication strategies more than female students. These results in the present study reflect those by Tannen (as cited in Salmani-Nodoushan, 2007) and Salmani-Nodoushan (2007) in that males and females learners applied conversational strategies differently. Moreover, Zack (1993) suggested that men and women don't have the same tendencies to use email communication.

The findings bear important implications for future email researches and generate appropriate pedagogic guidelines for EFL learners in their hierarchical relationships with their professors. In the light of the discussion and insights gained from this study, students should be educated on the proper and effective use of email. This research, in a nutshell, may be of use to EFL learners, teachers, curriculum developers, and ESP and EAP syllabus designers who can benefit from the results to understand and consider students' educational or academic needs.

Since Iranian EFL learners are not competent enough in email interaction, special courses such as academic writing instruction can be provided for students to learn how to write appropriate email messages, containing appropriate topics and strategies, to their instructors in academic context. In other words, it is needed to make students aware of the appropriate relationship between instructors and students in Iranian context via email channel. Moreover, EFL learners have problems in socio-cultural and pragma-linguistic types, they should be aware of socio-cultural and pragmatic norms of the target language. Teachers can encourage students to use email for many activities such as submitting their assignments and requesting for information which can be replaced with the face-to-face meetings. The role of email as a type of computer-mediated communication with dynamic nature could not be ignored in language education. The insights gained from the present research emphasize the pedagogical importance of computer-mediated communication, especially email communication.

\subsection{Suggestions for Further Research}

The exploratory nature of the research allowed for numerous areas to be examined including socioeconomic status, and demographic ones. The findings of this study are plentiful for future researchers of email communication. Perhaps the most interesting point of departure for future research arising from the study is to examine the influence of factors such as the power, social distance, and of the recipient in email messages among BA and MA students. Moreover, a study can be done with the focus on gender differences between MA and BA students in using communication topics and strategies. As also suggested by Biesenbach-Lucas (2007), longitudinal study exploring how the formality and structure of students' emails change during their four years of study may be another fruitful line of further research.

Another area for future study is to explore how emails sent to older instructors are different from email messages sent to younger instructors considering address terms, communication topics and communication strategies. Furthermore, a study can focus on using emotions in email messages sent by university students to their instructors for both BA and MA levels.

\section{References}

Biesenbach-Lucas, S. (2005). Communication topics and strategies in email consultation: comparison between American and international university students. Language Learning \& Technology, 9(2), 24-46.

Biesenbach-Lucas, S. (2007). Students writing emails to faculty: an examination of e-politeness among native and nonnative speakers of English. Language Learning \& Technology, 11(2), 59-81.

Bloch, J. (2002). Student/teacher interaction via e-mail: The social context of Internet discourse. Journal of Second Language Writing, 11(2), 117-134.

Boles, W. (1999). Classroom assessment for improved learning: A case study in using e-mail and involving students in preparing assignments. Higher Education Research \& Development, 18, 145-156.

Brosnan, M. J. (2006). Gender and diffusion of email: An organizational perspective. In Barrett, M., \& Davidson, M. J. (Eds.), Gender and communication at work (pp. 260-269). Aldershot: Ashgate.

Bulut, D., \& Rababah, G. (2007).Pragmatics of e-mail communication between Saudi female students and male professors. The JALT CALL Journal, 3(3), 49-73.

Chalak, A., Eslami-Rasekh, Z., \& Eslami-Rasekh, A. (2010). Communication strategies and topics in e-mail interactions between Iranian EFL students and their instructors. International Journal of Language Studies, 4(4), 129147.

Duran, R. L., Kelly, L., \& Keaten, J. A. (2005).College faculty use and perceptions of electronic mail to communicate with students. Communication Quarterly, 53(2), 159-176.

Fahim, M., Motallebzadeh, K., \& Sazegar (2011).The effect of e-mailing on vocabulary retention of Iranian lower intermediate EFL learners. Journal of Language Teaching and Research, 2(6), 1385-1391.

Gee, J. P. (2002). Literacies, identities, and discourses. In M. J. Schleppegrell \& M. C. Colombia (Eds.), Developing advanced literacy in first and second languages: Meaning with power (pp. 159-175). Mahwah, New Jersey: Lawrence Erlbaum Associates. 
Gui, M., \& Argentin, G. (2011). Digital skills of Internet natives: Different forms of Digital literacy in a Random sample of northern Italian high school students, New Media Society, 13(6), 936-980.

Herring, S. C. (1993). Gender and democracy in computer-mediated communication. Electronic Journal of Communication, 3(2). Retrieved June 2003, from http://www.cios.org/getfile/Herring_V3N293

Herring, S. C. (1994). Politeness in computer culture: Why women thank and men flame. Proceedings of the Third Berkeley Women and Language Conference (pp. 278-294). Berkeley Women and Language Group.

Hill, K., \& Monk, A. F. (2000). Electronic mail versus printed text: The effects on recipients. Interacting with Computers, 13(2), 253-263.

Hsu, H-Y., Wang, S., \& Comac, L. (2008). Using audio blogs to assist English-language learning: an investigation into student perception. Computer Assisted Language Learning, 21(2), 181-198.

Hurd, S., \& Murphy, L. (2005). Using ICT to support your language learning. Success with languages (pp. 161-172). Britain: Routledge.

Izadi, A., \& Zilaie, F. (2012). Politeness strategies in email exchanges in Persian. Journal of Comparative Literature and Culture, 2(1), 86-90.

Jackson, L. A., Samona, R., \& Moomaw, J. (2007). What do children do on the internet: Domains visited and their relationship to socio-demographic characteristics and academic performance. Cyber Psychology \& Behavior, 10(2), 182-190.

Janghorban, S., \& Ketabi, S. (2011). An investigation of e-mail writing in Persian learners of English: The effects of social distance and closeness on the formality of the written e-mails. The Iranian EFL Journal, 7(3), 254-278.

Jones, S. (2002, September 15). The Internet goes to the college: How students are living in the future with today's technology. Washington, DC: Pew Internet \& American Life Project. Retrieved April 2005, from http://www.pewinternet.org/reports/index.asp.

Martin, M. M., Myers, S. A., \& Mottet, T. P. (1999). Students' motives for communicating with their instructors. Communication Education, 48(2), 157-164.

Martin, M. M., Mottet, T. P., \& Myers, S. A. (2000). Students' motives for communicating with their instructors and affective and cognitive learning. Psychological Reports, 87, 830-834.

Motallebzadeh, K. (2011). Integrating emailing tasks into EFL reading comprehension classrooms. Journal of Language Teaching and Research, Poling, D. J. (1994). Email as an effective teaching supplement. Educational Technology, 34 (5), 53-55.

Mulac, A., Seibold, D. R. \& Farris, J. L. (2000). Female and male managers' professionals" criticism giving: Differences in language use and effects. Journal of Language \& Social Psychology, 19(4), 389-415.

Nasah, A., DaCosta, B., \& Kinsell, C. (2010). The Digital Literacy Debate: An Investigation of Digital Propensity and Information and Communication Technology. Educational Technology and Research Development, 58(5), 531-555.

Ning, H., Dai, X., \& Zhang, F. (2010). On gender difference in English language and its causes. Asian Social Science, 6(2), 126-130.

Papanis, E., Giavrimis, P., \& Papani, E. M. (2010). The contribution of the internet into learning. Review of European Studies, 2(1), 54-60.

Payne, C. R. (1997). Opening the door with e-mail: from no-tech to low-tech. Retrieved April 20, 2013, from http://tcc.kcc.hawaii.edu/previous/TCC\%201997/payne.html

Recchiuti, J. K. (2003). College students' uses and motives for e-mail, instant message, and online chat rooms. Unpublished master's thesis, University of Delaware, Newark, Delaware.

Rice, R. E., Sheperd, A., Dutton, W. H. \& Katz, J. E. (2007). Social interaction and the Internet: A comparative analysis of surveys in the US and Britain. In A.N. Joinson, K.Y. A. McKenna, T. Postmes, \& U. R. Reips (Eds.). Oxford handbook of Internet psychology (pp.7-30). Oxford: Oxford University Press.

Rossetti, P. (2000). Gender differences in e-mail communication. The Internet TESL Journal, 4(7). Retrieved from http://iteslj.org/Articles/Rossetti-GenderDif.html

Salmani-Nodoushan, M. A. (2007). Conversational strategies in Farsi complaints: The case study of Iranian complainees. Iranian Journal of Language Studies, 2(2), 187-214. Retrieved from http://www.ijls.net/

Samar, R. G., Navidinia, H., \&Mehrani, M. B. (2010). Communication purposes and strategies in email communication: A contrastive analysis between Iranian and American students. International Journal of Language Studies, 4(3), 55-72.

Savicki, V., Foster, D. A., \& Kelley, M. (2006). Gender, group composition, and task type in virtual groups. In M. Barrett \& M. J. Davidson, Gender and communication at work (pp. 270-282). Aldershot, UK: Ashgate Publishing Ltd.

Sheehan, K. B. (1999). An investigation of gender differences in on-line privacy concerns and resultant behaviors. Journal of Interactive Marketing, 13(4), 24-38.

Smith, C. D., Whiteley, H. E., \& Smith, S. (1999). Using email for teaching. Computers \& Education, 33, 15-25. 
Tannen, D. (1990). You just don't understand: Women and men in conversation. New York: William Morrow.

Uhlirova, L. (1994). E-mail as a new subvariety of medium and its effects upon the message. In S. Cmejrkova\& F. Sticha (Eds.). The syntax of sentence and text: Festschrift for Frantisek Danes (pp. 273-282). Amsterdam: John Benjamins.

Weiser, E. B. (2000). Gender differences in internet use patterns and Internet application preferences: A two-sample comparison. Cyber Psychology \& Behavior, 3(2), 167-178. Abstract retrieved from http://connection.ebscohost.com/.../gender-differences-internet-use-patterns

Zare, P. (2010). An investigation into language learning strategy use and gender among Iranian undergraduate language learners. World Applied Science Journal, 11(110), 1238-1247.

Zack, M. H. (1993), Interactivity and communication mode choice in ongoing management groups. Information System Research, 4(3), 207-239. 